\title{
COVID-19 Pandemic in Nigeria: A review
}

Elikwu CJ1, Walker $\mathrm{O}^{2}$

\author{
${ }^{1}$ Department of Medical Microbiology, Benjamin Carson College of Medicine, Babcock University, llishan- \\ Remo, Ogun State, Nigeria. \\ ${ }^{2}$ Department of Pharmacology, Benjamin Carson College of Medicine, Babcock University, Ilishan-Remo, \\ Ogun State, Nigeria.
}

\begin{abstract}
Background: An ongoing outbreak of pneumonia associated with a novel coronavirus was reported in Wuhan city, China. This new virus was named severe acute respiratory syndrome coronavirus 2 (SARS-CoV-2) by the Coronavirus Study Group (CSG) of the International Committee on Taxonomy of Viruses. That disease, caused by the SARS-CoV-2, has been named coronavirus disease 2019 (COVID-19) by the WHO. The outbreak has since spread across the globe, including countries in Africa.

Main body: The dominant mode of transmission is from the respiratory tract, via droplets or indirectly via fomites, and to a lesser extent via aerosols.

The rapidity with which the infection spread throughout the world was unexpected. The disease has now affected 212 countries, areas, or territories, with more than 2.1 million total confirmed cases and over 144 thousand fatalities as at the time of writing. It, therefore, behooves countries of the world to take firm public health measures for the pandemic is to be contained.

Conclusion: Nigeria, with a population of at least 170 million people, is of global interest because a rapid rise in the number of infected people will have serious implications not only for the country but for the whole African continent.
\end{abstract}

Keywords: 2019-nCOV, SARS-CoV-2, COVID-19, Pneumonia, Acute Respiratory Distress syndrome, Nigeria

\section{Background}

A local outbreak of pneumonia of initially unknown cause was detected in Wuhan (Hubei, China), and was quickly determined to be caused by a novel coronavirus, namely severe acute respiratory syndrome coronavirus 2 (SARS-CoV2) and was reported to WHO in December 2019 $(1,2,3)$. The disease caused by the SARS-CoV2 has been named COVID-19 by WHO $(1,2)$. The outbreak has since spread across about 212 countries, areas or territories of the world, with more than 2,165,586 total confirmed cases and 144,341 total deaths as of April 16, 2020 (4, 5); a significant proportion of the active cases $(1,474,976)$ are cases with mild conditions $(96 \%)$ while only $4 \%$ are either serious or critical cases. Of the 605,639 cases which had an outcome, $(79 \%)$ have recovered or been discharged, leaving (21\%) dead (6).

The current COVID-19 pandemic is an event of international significance and arguably one of the

Correspondence: Oladapo Walker.

Department of Pharmacology,

Benjamin Carson College of Medicine,

Babcock University, Ilishan, Ogun State, Nigeria

+2348129438279; oladapo.walker@gmail.com largest pandemics the world has had in modern times. This particular pandemic walks in the footprints of the 1918-1919 influenza AH1N1 pandemic, which affected about 500 million people with an estimated mortality of 50-100 million (7). This antecedent, therefore, makes the current pandemic important as the world has no interest in reaching the milestones of 1918-1919. The current pandemic, according to Chinese sources, started in the sea-food market of Wuhan in December 2019 (8). The patients, all of whom had pneumonia, were deemed to have been infected with a new coronavirus strain temporarily named 2019-nCov by WHO in January 2020 (9, 10). Scientific records show that the first human coronavirus infection was identified in the 1960s (11), and 2019-nCov is the seventh strain of coronavirus to infect man (12). The review by Cui et al. (12) shows that the reservoir is largely bats or rats. The last SARS of 2003 was deemed to have come from bats, transmitted to pigs, and

(C) BUMJ. 2020 Open Access This article is distributed under the terms of the Creative Commons Attribution 4.0 International License (http://creativecommons.org/licenses/by/4.0/), which permits unrestricted use, distribution, and reproduction in any medium, provided you give appropriate credit to the original author(s) and the source, provide a link to the Creative Commons license, and indicate if changes were made. The Creative Commons Public Domain Dedication waiver (http://creativecommons.org/publicdomain/zero/1.0/) applies to the data made available in this article, unless otherwise stated. 
ultimately man $(12,13,14,15)$. It has been shown that there are at least 29 animal species that serve as reservoirs for coronavirus (12).

Coronaviruses are enveloped positive-sense RNA viruses ranging from $60 \mathrm{~nm}$ to $140 \mathrm{~nm}$ in diameter with spike-like projections on its surface, giving it a crown-like appearance under the electron microscope; hence the name coronavirus (16). Coronaviruses were first described in 1966 by Tyrrell and Bynoe, who cultivated the viruses from patients with common colds (17). Four subfamilies, namely alpha-, beta, gamma- and delta coronaviruses exist. While alpha- and beta-coronaviruses originate from mammals, in particular from bats, gamma- and delta-viruses originate from pigs and birds. The genome size varies between $26 \mathrm{~kb}$ and $32 \mathrm{~kb}$. Among the seven subtypes of coronaviruses that can infect humans, the beta-coronaviruses may cause severe disease and fatalities, whereas alpha-coronaviruses cause asymptomatic or mildly symptomatic infections. SARS-CoV-2 belongs to the $B$ lineage of the betacoronaviruses and is closely related to the SARSCoV virus (18). Four coronaviruses namely HKU1, NL63, 229E, and OC43 have been in circulation in humans, and they generally cause mild respiratory disease. The major four structural genes encode the nucleocapsid protein $(N)$, the spike protein (S), a small membrane protein (SM) and the membrane glycoprotein (M) with an additional membrane glycoprotein (HE) occurring in the HCoV-OC43 and HKU1 betacoronaviruses (19). As reviewed by Singhal (20), Coronaviruses have been associated with two events in the past two decades, where a crossover of animal beta coronaviruses to humans resulted in severe disease. The first event was in 2002- 2003, when a new coronavirus of the $\beta$-genera and with origin in bats crossed over to humans via the intermediary host of palm civet cats in the Guangdong province of China. This virus, called severe acute respiratory syndrome coronavirus, affected 8,422 people mostly in China and Hong Kong and caused 916 deaths with a mortality rate of $11 \%$ before being contained (21). Almost a decade later in 2012, the Middle East respiratory syndrome coronavirus (MERS-CoV), also of bat origin, first reported in Saudi Arabia with dromedary camels as the intermediate host in which a total of 2494 laboratory-confirmed cases including 858 associated deaths (case-fatality rate $34.4 \%$ ) were reported globally (22). As reviewed in a study (15), Phylogenetic studies of the SARS-CoV-2 showed it shared about $79 \%$ nucleotide homology with SARS-CoV $(14,23)$, as well as to two SARS-like coronaviruses isolated from Chinese horseshoe bats (Rhinolophus sinicus) in Zhoushan, with which it shared $89 \%$ nucleotide homology $(23,24)$, and to a third SARS-like coronavirus from an Intermediate horseshoe bat ( $R$. affinis), with which it shared $96 \%$ nucleotide homology $(14,25)$. Thus SARSCoV-2 is classified as a Betacoronavirus $2 \mathrm{~B}$ lineage (WHO) $(15,26,27)$.

Some surveillance, molecular epidemiology, and eco-epidemiological studies $(28,29,30,31,32$, 33) have shown horseshoe and Rhinolophus bats, in different areas of China serves as the reservoir for a large number of SARS-related coronaviruses (SARSr-CoV). Quite a significant recombination event occurs between the precursors of these SARSr-CoVs leading to the hypothesized provenance of the direct progenitor of SARS-CoV. These studies provide new insights into the origin and evolution of SARSCoV and highlight the necessity of preparedness for the future emergence of SARS-like diseases. These in our thoughts lend credence to why the outbreaks of coronavirus have commonly started in China.

\section{The emergence of COVID-19 in Nigeria}

The population of Nigeria is estimated to be about 170 million (34). The health system is weak. Poor distribution of human resources, lack of technologies, poor logistics, and supplies with poor adherence to policies has beleaguered the health system for many years $(35,36,37,38)$.

The weak health system makes it imperative, that the world would be interested in the propagation of the COVID-19 virus when it appears in Nigeria. The first case reported in Nigeria, according to the Nigerian Centre for Disease Control (NCDC) (39), was on the $27^{\text {th }}$ of February 2020 . As at the time of writing, 407 total confirmed cases and 12 deaths have been reported by NCDC (40). The case-fatality rate of $3.0 \%$ in Nigeria is similar to what has been reported $(20,41,42,43)$ with China (3.9), Italy (12.7) at the time of writing. It was recorded that the number of new cases has increased exponentially in other countries, including Italy. However, the spread of the disease in Nigeria appears to be slower than observed in China and Italy as evident by the total Cases per 1 million population of Nigeria (2) compared to China $(57)$ and Italy $(2,586)(6)$.

The picture of COVID-19 in Nigeria (39) The index case of COVID-19 arrived in Nigeria via the Murtala Muhammed International Airport, 
Lagos at 10 pm on 24th February 2020 aboard Turkish airline from Milan, Italy- the European epicenter of COVID-19 outbreak. Italy had over 152 thousand total confirmed cases and over 19 thousand deaths at that time (44). He traveled on to his company site in Ogun state on 25th February. On 26th February, he presented at the staff clinic in Ogun, and there was a high index of suspicion by the managing physician. He was referred to Infectious Disease Hospital (IDH) in Lagos and COVID-19 was confirmed on 27th February 2020. The second case was reported on $9^{\text {th }}$ March, at Ewekoro. This case had contact with the index case from Italy. By the end of March, there were 151 cases and four deaths. As at the time of writing over a total of 5000 COVID19 tests have been conducted and there have been 373 total confirmed cases, 11 deaths and 99 discharged. The latest available updates from the NCDC situation report (45) showed details of the cases' provenance as travel history - 144 $(47 \%)$, contacts - $88(29 \%)$, unknown source -6 $(2 \%)$, and incomplete $-67(22 \%)$. Males 221 $(72 \%)$ are more affected than females $84(28 \%)$, which is in line with the global picture (46). Table I summarizes the COVID-19 cases in Nigeria (40). The NCDC data in the public domain shows that over $50 \%$ of those who reported that they had symptoms of the COVID-19 were imported cases. Their ports of disembarkation were Lagos and Abuja international airports and a few others through the land border of Nigeria with the Republic of Benin. It has been observed that the evolution of the outbreak in Nigeria appears to be slower than in Italy because, within nine days of the outbreak, there were about 1,000 cases in the infectious disease hospital in Northern Italy (47), which is not the case in Nigeria. However, Tuite et al estimated that the outbreak in Italy probably started one month earlier than reported, and the size of the epidemic much larger than current estimates (48).

Underreporting of outbreak numbers is common (48). Nevertheless, from the records obtained from NCDC, the index case could be traced only to the $27^{\text {th }}$ of February 2020 . This fact does not, in any way, undermine the issue of underreporting of the people affected by the epidemic. Similarly, in China, the progression of the epidemic appeared to have been very rapid, as within one and a half months more than 75,000 people in 25 countries had been infected (49).

\section{Clinical Presentation}

The clinical features of COVID-19 are varied, ranging from non-symptomatic state to severe pneumonia with acute respiratory distress syndrome, multi-organ dysfunction, and death (50). According to the WHO-China Joint Mission document (27), as of 20 February 2020 and based on 55,924 laboratory-confirmed cases, typical signs and symptoms include fever $(87.9 \%)$, dry cough $(67.7 \%)$, fatigue $(38.1 \%)$, sputum production $(33.4 \%)$, shortness of breath $(18.6 \%)$, sore throat $(13.9 \%)$, headache $(13.6 \%)$, myalgia or arthralgia (14.8\%), chills $(11.4 \%)$, nausea or vomiting $(5.0 \%)$, nasal congestion $(4.8 \%)$, diarrhea $(3.7 \%)$, and hemoptysis $(0.9 \%)$, and conjunctival congestion (0.8\%). Thus, COVID-19 features are indistinguishable from other respiratory infections. People with COVID19 generally develop signs and symptoms, including mild respiratory symptoms and fever, on an average of 5-6 days after infection (mean incubation period 5-6 days, range 1-14 days) (27). In a subset of patients, by the end of the first week, the disease can progress to pneumonia, respiratory failure, and death. This progression is associated with an extreme rise in inflammatory cytokines including IL2, IL7, IL10, GCSF, IP10, MCP1, MIP1A, and TNFa (51). The presentation of the disease from the patients seen in Nigeria has been that of a mild upper respiratory illness that consists of fever, arthralgia, mild dry cough, weakness, and sometimes mild gastrointestinal symptoms (52). This presentation is not very different from what was observed in China (24) and Italy (53).

In China, two groups of people were identified; those who did not progress beyond a mild disease and those who progressed to more severe disease and presented like acute respiratory distress syndrome (SARS) (49); this happened to align with global pattern $(27,46)$. In Italy, mathematical modeling in February of 2020 showed that the disease may grow exponentially, which is what has happened (54). Also, the authors noted that $9-11 \%$ of the people infected with COVID-19 needed to be in intensive care. 
Table I: CASE SUMMARY IN NIGERIA AS AT APRIL 12TH 2020 (40)

\begin{tabular}{|l|c|c|c|c|}
\hline States Affected & $\begin{array}{c}\text { No. of Cases } \\
\text { (Lab Confirmed) }\end{array}$ & $\begin{array}{c}\text { No. of Cases } \\
\text { (on admission) }\end{array}$ & $\begin{array}{c}\text { No. } \\
\text { Discharged }\end{array}$ & $\begin{array}{c}\text { No of } \\
\text { Deaths }\end{array}$ \\
\hline Lagos & 214 & 139 & 69 & 6 \\
\hline Abuja FCT & 58 & 45 & 11 & 2 \\
\hline Osun & 20 & 9 & 11 & 0 \\
\hline Edo & 15 & 14 & 0 & 1 \\
\hline Oyo & 11 & 7 & 4 & 0 \\
\hline Ogun & 9 & 7 & 2 & 0 \\
\hline Bauchi & 6 & 6 & 0 & 0 \\
\hline Kaduna & 6 & 6 & 0 & 0 \\
\hline Akwa Ibom & 6 & 6 & 0 & 0 \\
\hline Katsina & 5 & 4 & 0 & 1 \\
\hline Kwara & 4 & 4 & 0 & 0 \\
\hline Kano & 4 & 4 & 0 & 0 \\
\hline Delta & 3 & 2 & 0 & 1 \\
\hline Ondo & 3 & 3 & 0 & 0 \\
\hline Enugu & 2 & 2 & 0 & 0 \\
\hline Ekiti & 2 & 1 & 1 & 0 \\
\hline Rivers & 2 & 1 & 1 & 0 \\
\hline Benue & 1 & 1 & 0 & 0 \\
\hline Niger & 1 & 1 & 0 & 0 \\
\hline Anambra & 1 & 1 & 0 & 0 \\
\hline Total & 373 & $\mathbf{2 6 3}$ & 99 & 11 \\
\hline
\end{tabular}

\section{Transmission}

As reviewed by Rudan, Igor (55) several factors were responsible for the exponential increase in COVID-19 transmission in Italy and other European countries. Northern Italy could have played host to Chinese tourists from Wuhan in January and February 2020. Since fever does not accompany all COVID-19 cases and asymptomatic transmission is possible, infected tourists could have been allowed to enter Italy even where proper checks at the airports were in place (56). Most infected people from northern Italy spent their weekends at European ski resorts. Although it is not known if COVID-19 transmission will be stemmed by warmer weather it was assumed that the cold helped spread the virus. That is why European ski resorts became real nurseries of coronavirus in late February and in early March, as many media reported. It was known that sports like European Champions League were still being held across Europe and in Italy and Spain in particular. Such games attract fans in their thousands across the two countries. Specifically, on the 19th of February, a Champions League football match was held between Italy's Atalanta and Spain's Valencia. This means a significant proportion of Bergamo's (Italy's host city) population wandered the streets of Milan before the game and has the host team scored four goals in the match, a third of Bergamo's population was hugging and kissing in the cold weather four times and spent the day closely together. This is likely why it became the worst-hit region of Italy by some distance. Unfortunately for Spain, nearly 2500 Valencia fans also travelled to the match. Moreover, at least a third of Valencia football squad also got infected with a virus and later played another team in the Spanish league, where further players of that team got infected. This football game has certainly contributed to the virus making its way to Spain. Another possible factor, it is very important for the early determination of the epidemiological situation in each country to look at which subset of the population the virus has spread among. For Italy, its Northern region has a very large number of very old people. Hence, in the early stages of the epidemic, the virus began to spread in hospitals and retirement homes. They did not have nearly enough capacities to assist in severe cases and the virus spread more easily and faster among already sick, elderly and immunocompromised people and had a significantly higher death rate. Lastly, a likely most important factor required to explain the current situation in Italy and other European Union (EU) countries includes, either the omission to monitor the mathematical parameters 
of the epidemic, or perhaps the lack of clear communication of the dangers, or the indecisiveness to adopt isolation measures for the population (55).

Major determinants of COVID-19 fatality are elderly (recent studies indicate that patients $\geq 60$ years of age are at higher risk than children who might be less likely to become infected or if so, may show milder symptoms or even asymptomatic infection) (57), immunocompromised persons with preexisting medical conditions like Cardiovascular disease $(13.2 \%)$, Diabetes $(9.2 \%)$, Chronic respiratory disease $(8.0 \%)$, Hypertension $(8.4 \%)$, Cancer $(7.6 \%)(46)$.

In Nigeria, from the evidence obtained from the first two patients with COVID-19 disease, it can be safely assumed that the major route of transmission in the country after the first imported case (39) is by person to person via respiratory droplets (52). Droplet transmission occurs when respiratory droplets generated via coughing, sneezing or talking contact susceptible mucosal surfaces, such as the eyes, nose, or mouth. Transmission may also occur indirectly via contact with contaminated fomites with hands and then mucosal surfaces. Respiratory droplets are large and are not able to remain suspended in the air, thus they are usually dispersed over short distances. This has been the major route of transmission for the Chinese, Italian, French, and Spanish cases recorded $(24,47,48,49,58,59$, $60,61)$. From the index case, and NCDC records, it is evident that the outbreak started from the importation of the virus, and later cases were due to community transmission from person to person. This is worthy of note as Nigeria is a tropical country with a large population of bats, especially in the south of the country. As the Chinese researchers have established a large number of SARS-related coronaviruses (SARSrCoV) in homeland bats we too need to establish epidemiological surveillance in search and characterization of SARSr-CoV in Nigerian bats. Whether these viruses will ultimately be found in bats and serve as a reservoir for further infections is yet to be ascertained. The Nigerian Ministry of Health, in conjunction with Funding partners, needs to liaise with the academia to research this and find ways and means of containing the virus, so that we do not have a large animal reservoir which may become troublesome.

\section{Diagnosis}

Diagnostic testing for COVID-19 is critical to tracking the virus, understanding the epidemiology, informing case management, and suppressing transmission (62).

Clinical diagnosis is based on national case definition (63). A suspected case is defined as a person (including severely ill patients) with fever, cough, or difficulty in breathing, who within 14 days before the onset of illness had a history of travel to and more than 24 hours transit through to any high-risk country with widespread community transmission of SARS-CoV-2 or had close contact with a confirmed case of COVID-19 or had exposure to a healthcare facility where COVID-19 case(s) have been reported or contact with patients with similar travel history. However, cases may be asymptomatic or even without a fever. A probable case is any suspect case for whom testing for COVID-19 yielded indeterminate test results or for whom testing was positive on a pan-coronavirus assay or where samples were not collected before the demise of a suspect case but is epidemiologically linked to a confirmed case. A confirmed case is a suspect case with a positive molecular test with or without signs and symptoms.

COVID-19 Healthcare worker infection: any healthcare worker with moderate to severe respiratory illness reporting recent contact $(<14$ days) with patients with a recent history of travel abroad and respiratory symptoms will be considered a suspect case (64).

Though commercial kits for testing are not yet available in Nigeria for widespread COVID-19 testing, there are presently eleven NCDC accredited molecular laboratories (40) where testing is being carried out by the real timereversed transcriptase PCR (9). The COVID-19 molecular laboratories where testing is conducted are Lagos (Lagos University Teaching Hospital, Nigeria Institute of Medical Research and Lagos State Biosafety Level 3 laboratory), Virology laboratory University College Hospital, Ibadan, African Center of Excellence for Genomics of Infectious Diseases, Ede, Osun State, Irrua Specialist Teaching Hospital, Edo State; Federal Teaching Hospital Abakaliki (FETHA), Ebonyi State, NCDC National Reference Laboratory, Gaduwa, Abuja, Defence Laboratory Abuja, Jos University Teaching Hospital and Aminu Kano University Teaching Hospital Other sites are in progress (Figure I) (39). 


\section{NCDC MOLECULAR LABORATORY NETWORK}

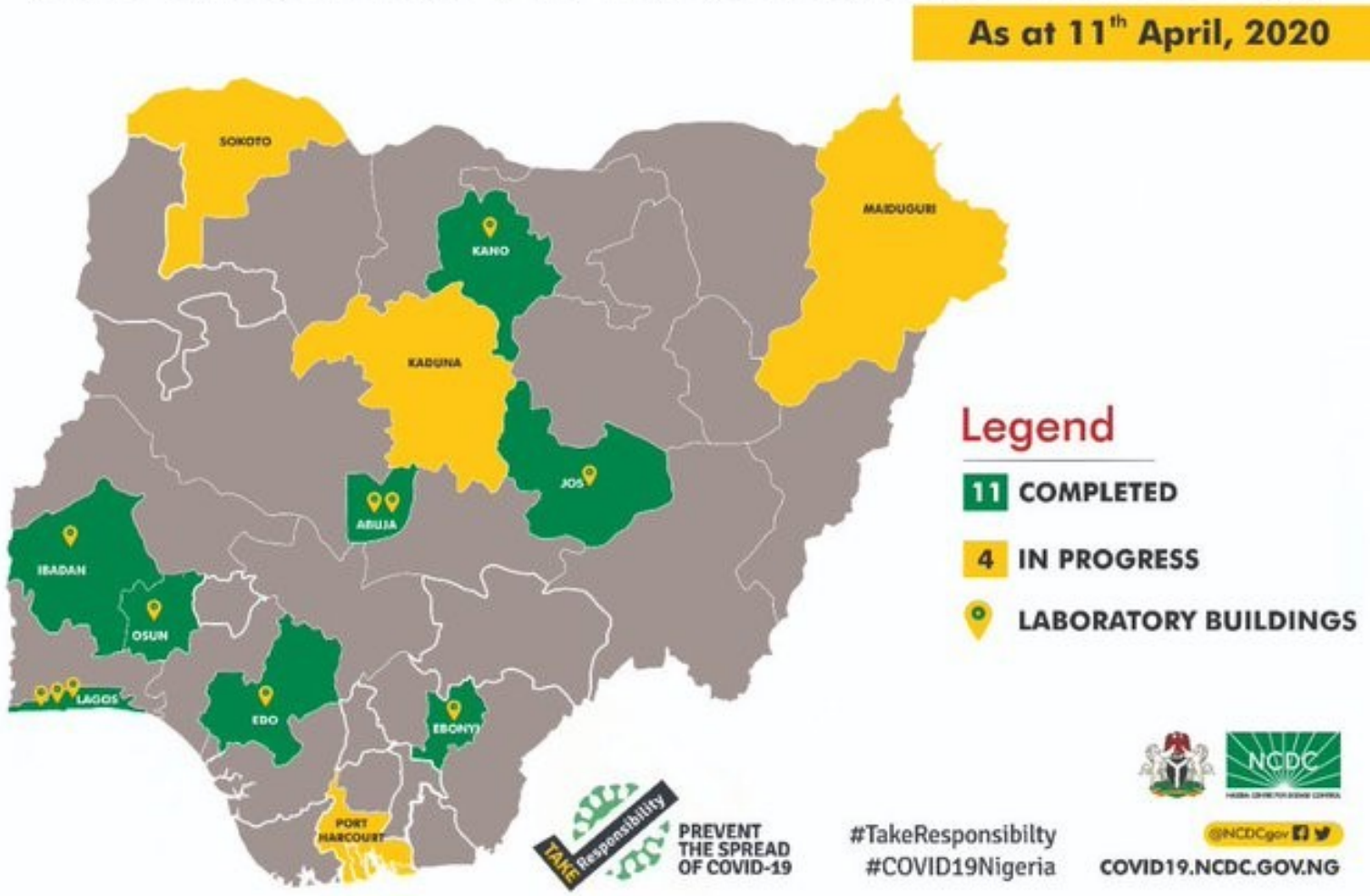

Some studies $(50,65)$ have shown that varying clinical specimens ranging from Pharyngeal swabs, Blood, sputum, feces, urine, and nasal samples; Bronchoalveolar lavage (BAL) fluid and fiber bronchoscopic brush biopsy were collected from patients with severe illness or undergoing mechanical ventilation may be collected for testing. In one of the studies (65), 1070 specimens were collected from 205 patients with COVID-19 who were a mean age of 44 years (range, 5-67 years) and 68\% male. Bronchoalveolar lavage fluid specimens showed the highest positive rates (14 of $15 ; 93 \%$ ), followed by sputum (72 of $104 ; 72 \%$ ), nasal swabs (5 of $8 ; 63 \%)$, fiber bronchoscope brush biopsy (6 of $13 ; 46 \%)$, pharyngeal swabs (126 of $398 ; 32 \%$ ), feces (44 of $153 ; 29 \%$ ), and blood (3 of $307 ; 1 \%)$. None of the 72 urine specimens tested positive. Inadequate or inappropriate specimen collection, storage, and transport are likely to yield false test results. Training in specimen collection is highly recommended due to the importance of specimen quality (66).
However, the National Interim Guidelines for Clinical Management of COVID-19 disease (52, 66) currently recommends the collection of the nasopharyngeal swab, oropharyngeal swab with the use of synthetic fiber swabs (nylon or Dacron) with plastic shafts in patients with mild disease; Sputum may also be collected if it can be produced. While endotracheal aspirate or bronchoalveolar lavage (if the patient is intubated) is recommended for severely ill patients.

According to the study above nasal swab is not the optimal specimen but it is easy and less cumbersome to collect and also less likely to generate aerosol than bronch-alveolar lavage (BAL); whether this has been responsible for some of the near diagnostic misses in some of our testing centers is yet to be established. Perhaps, a review of our national diagnostic protocol may be a prudent consideration given the rapidly evolving COVID-19 phenomenon. The NCDC COVID-19 document (67) provides detailed information on specimen collection, transportation guidance, risk assessment and 
appropriate use of PPE. Laboratory confirmation of the COVID-19 case is presently by real-time RT-PCR targeting the open reading frame $1 a b$ gene of SARS-CoV-2 as previously described (50); other protocols depending on the country are available (66). The standard turnaround time for COVID-19 molecular diagnosis is $48-72$ hours.

\section{Any role for the rapid diagnostic tests (RDTs)?}

There has been much hype about rapid test kits for COVID-19 testing. The first category of RDTs is the rapid test kits that target the antibody mounted by the body against the virus and results ready within minutes or hours after extracting a blood sample from a patient. Because antibodies take time to develop, antibody tests are not favored to definitively diagnose coronavirus. The rapid test kits could give a "false-negative" result. A "false-positive" result due to cross-reaction with other bacteria or viruses is also possible. Hence, a confirmatory PCR based test is still required for the definitive diagnosis of COVID-19. It is important to note that the equipment and materials used for the test should also be disposed of properly to prevent the spread of COVID-19 and other diseases. The USA Food and Drug Administration has recently granted an Emergency Use Authorization for five new commercial rapid test kits (68). The second category of RDT is the Cepheid's GeneXpert machine which microfluidics-based rapid testing system proved itself during the 2001 anthrax attacks (69) in the USA and has been adapted to test for flu, strep, norovirus, chlamydia, tuberculosis, MRSA over the years-and now, COVID-19. In late March, the FDA approved the use of Cepheid's GeneXpert rapid molecular diagnostic machines for the qualitative detection of SARS-CoV-2, the virus that causes COVID-19. The test leverages the design principles of the current Xpert $\AA$ Xpress Flu/RSV cartridge technology (70), in which multiple regions of the viral genome are targeted. The test generates accurate results in about 45 minutes with less than a minute of hands-on time to prepare the sample. The automated modules- 5000 of which are already installed in U.S. health facilities, while 18,000 are in operation in other countries-don't require a lab facility or special training to operate. The modules use disposable cartridges, pre-filled with the required chemicals that are channeled around test chambers using microfluidics. Cepheid GeneXpert is also among several testing systems under evaluation by the NHS (71). The
Cepheid GeneXpert will not in any way harm the ongoig tuberculosis control programme.

Other laboratory investigations are usually nonspecific. The white cell count is usually normal or low. There may be lymphopenia; a lymphocyte count $<1000$ has been associated with severe disease. The platelet count is usually normal or mildly low. The CRP and ESR are generally elevated, but procalcitonin levels are usually normal. A high procalcitonin level may indicate a bacterial co-infection. The ALT/AST, prothrombin time, creatinine, D-dimer, CPK, and LDH may be elevated, and high levels are associated with severe disease (20). Chest X-ray (CXR) usually shows bilateral infiltrates but may be normal in early disease. Computerized tomography (CT) is more sensitive and specific. CT imaging generally shows infiltrates, groundglass opacities, and sub-segmental consolidation. Perhaps the most striking COVID19 feature of CT is that it is abnormal in asymptomatic patients/ patients with no clinical evidence of lower respiratory tract involvement. Abnormal CT scans have been used to diagnose COVID-19 in suspect cases with a negative molecular diagnosis; many of these patients had positive molecular tests on repeat testing (72).

Clinical Management of COVID-19 (52)

According to National Interim Guidelines for Clinical Management of COVID-19, Clinical management of COVID-19 is guided by general principles of management of respiratory illnesses. As there is ongoing research that made management very dynamic at the moment, there will be regular updates as more evidence emerges. It is important to note that currently, there are no specific vaccines or treatments for COVID-19. However, many ongoing clinical trials are evaluating potential treatments (73).

The clinical management of COVID-19 is classified under 1) the management of mild cases and 2 ) the management of severe cases $(27,52)$.

\section{Management of Mild Cases}

This applies to patients who may have nonspecific symptoms such as fever, cough, sore throat, nasal congestion, malaise, headache, and muscle pain. Some patients may be asymptomatic. Early symptomatic treatment and careful monitoring are recommended for a favorable outcome. Manage symptoms of fever, coughs, sore throat, nasal congestion, malaise, headache, and muscle pain - with antipyretics, cough medicine, rest. Close monitoring of all vital signs; rest, oral hydration is also carried out. 
There have been spread online of claims among the scientific community that drugs like Ibuprofen and other NSAIDS could weaken the immune system's attempts to battle the COVID-19 virus. However, there is insufficient evidence to establish a link between ibuprofen use and the likelihood of getting coronavirus or of having worse symptoms of the disease. A review by the Commission on Human Medicines (a Government panel of experts that advises ministers on the safety of medicines) concluded that both paracetamol and ibuprofen are safe to take for COVID-19 symptoms including fever and headache (74).

\section{Management of Severe Cases}

This applies to Adults patients with fever $\left(>38^{\circ} \mathrm{C}\right)$ or suspected respiratory infection AND one of the following: Respiratory rate $>30$ breaths/minute, Severe respiratory distress, $\mathrm{SpO}_{2}<90 \%$ on room air. The elderly and immunosuppressed patients may present with atypical symptoms.

Patients with mild pneumonia may progress to the severe form of the disease and thus require close monitoring. Children with severe COVID-19 infection will typically present with cough or difficulty in breathing AND at least one of the following: Central cyanosis or $\mathrm{SpO}_{2}<92 \%$, Severe respiratory distress e.g. grunting, very severe chest in-drawing, Signs of pneumonia with a general danger sign.

A 6-week old baby of a mother returning from the UK was the youngest COVID-19 patient Nigeria has ever had as at the time of this write-up. Both mother and baby fully recovered and were discharged.

\section{Prevention}

In line with practices in China, Italy, Spain, UK, and the US, the Nigerian government has ordered a total lockdown in the three strategic States of Lagos and Ogun, and Abuja. Other affected States have also introduced similar measures, with some States proactively following the same footprint.

Common public health practices used to protect the public by preventing exposure to people who have or may have a contagious disease are isolation and quarantine. Isolation separates sick people with a contagious disease from people who are not sick. Quarantine separates and restricts the movement of people who were exposed to a contagious disease to see if they become sick. These people may have been exposed to a disease and do not know it, or they may have the disease but do not show symptoms
(75). Isolation and quarantine can be voluntary or imposed by law (mandatory). Concerning COVID-19, Self-quarantine is staying in place, either at home or elsewhere, for 14 days because you have been exposed to someone who has tested positive for COVID-19. Self-isolation would be restricting movement a section of the house, away from the family within the house after you start showing symptoms of COVID-19. Social distancing is a response in which people remain home and distant from others (such as by refraining from shaking hands or hugging or going to the store at off hours), without any known exposure to the virus, to limit possible transmission to or from others (76).

Quarantines and travel bans are often the first response against new infectious diseases. Governments have imposed quarantines and travel bans on an unprecedented scale during this pandemic around the globe. China, for instance, locked down whole cities while Italy imposed draconian restrictions throughout the country. Even in the United States, thousands of people have been subjected to legally enforceable quarantines or are in "selfquarantine" (77). The same measures are currently being enforced in the two Nigerian states of Lagos, Ogun, and FCT to flatten the epicurve.

However, as reviewed by Parmet and Sinha (77), these old tools are usually of limited utility for highly transmissible diseases, and if imposed with too heavy a hand, or in too haphazard a manner, they can be counterproductive (78). With a virus such as SARS-CoV-2, they cannot provide a sufficient response. Inside the country, isolation and quarantine orders have traditionally come from the states, powered by the Quarantine Act of 1926, which remains the active law governing public health in emergencies in Nigeria today (79). While the lockdown is in place, the standard preventive measures to reduce the risk of spread of COVID-19, are being frequently relayed to members of the public to adhere to. These precautions include the following measures (40):

1. Frequently handwashing with soap under running water for at least 30 seconds or use alcohol-based hand rub (hand sanitizer), if Water is not available or the hand is not soiled.

2. Avoid close contact with anyone showing symptoms of respiratory illness. Maintain at least two meters ( 5 feet) distance between self and anyone who is coughing or sneezing repeatedly. 3. Cough etiquette by covering of mouth and nose properly with a tissue paper when sneezing 
and/or coughing. Dispose of the tissue properly immediately after use and proceed to handwashing, thereafter. Cough into one's elbow if a tissue is not available.

4. Do not mingle with people or congregate if you feel unwell with symptoms like fever, cough, sneezing or difficulty breathing.

\section{Use of masks in the context of COVID-19}

Current information suggests that the two main routes of transmission of the COVID-19 virus are respiratory droplets and contact. There is current evidence on transmission from symptomatic, presymptomatic, and asymptomatic people infected with COVID-19 (80). Current evidence suggests that most disease is transmitted by symptomatic laboratory-confirmed cases. In a small number of reports, the pre-symptomatic transmission has been documented through contact tracing efforts and enhanced investigation of clusters of confirmed cases $(81,82)$.

Medical masks are defined as surgical or procedure masks that are flat or pleated (some are shaped like cups); they are affixed to the head with straps. Wearing a medical mask is one of the prevention measures that can limit the spread of certain respiratory viral diseases, including COVID-19. However, the use of a mask alone is insufficient to provide an adequate level of protection- mask should be applied within the context of a bundle of measures (83). Whether or not masks are used, maximum compliance with hand hygiene and other IPC measures is critical to prevent human-to-human transmission of COVID-19.

\section{Community settings and mask usage}

There is limited evidence to prove that wearing a medical mask by healthy individuals in the households or among contacts of a sick patient, or by attendees of mass gatherings may be beneficial as a preventive measure $(84,85)$. However, there is currently no evidence that wearing a mask (whether medical or other types) by healthy persons in the wider community setting, including universal community masking, can prevent them from infection with respiratory viruses, including COVID-19. The use of medical masks in the community may create a false sense of security, with neglect of other essential measures, such as hand hygiene practices and physical distancing, and may lead to touching the face under the masks and under the eyes, unnecessary costs, and take masks away from those in health care who need them most, especially when masks are in short supply (83).
Persons with symptoms should wear a medical mask, self-isolate, and seek medical advice as soon as they start to feel unwell. It is important to note that early symptoms for some people infected with COVID-19 may be very mild; follow instructions on how to put on, take off, and dispose of medical masks; follow all additional preventive measures, in particular, hand hygiene and maintaining physical distance from other persons (83).

All persons should avoid groups of people and enclosed, crowded spaces; maintain a physical distance of at least $1 \mathrm{~m}$ from other persons, in particular from those with respiratory symptoms (e.g., coughing, sneezing); perform hand hygiene frequently, using an alcohol-based hand rub if hands are not visibly dirty or soap and water when hands are visibly dirty; cover their nose and mouth with a bent elbow or paper tissue when coughing or sneezing, dispose of the tissue immediately after use, and perform hand hygiene; refrain from touching their mouth, nose, and eyes (83).

\section{Home care}

Persons with suspected COVID-19 or mild symptoms should self-isolate if isolation in a medical facility is not indicated or not possible; perform hand hygiene frequently, using an alcohol-based hand rub if hands are not visibly dirty or soap and water when hands are visibly dirty; keep a distance of at least $1 \mathrm{~m}$ from other people; wear a medical mask as much as possible; the mask should be changed at least once daily. Persons who cannot tolerate a medical mask should rigorously apply respiratory hygiene (i.e. cover mouth and nose with a disposable paper tissue when coughing or sneezing and dispose of it immediately after use or use a bent elbow procedure and then perform hand hygiene.); avoid contaminating surfaces with saliva, phlegm, or respiratory secretions; improve airflow and ventilation in their living space by opening windows and doors as much as possible.

Caregivers or those sharing living space with persons suspected of COVID-19 or with mild symptoms should perform hand hygiene frequently, using an alcohol-based hand rub if hands are not visibly dirty or soap and water when hands are visibly dirty; keep a distance of at least 1 meter from the affected person when possible; wear a medical mask when in the same room as the affected person; dispose of any material contaminated with respiratory secretions (disposable tissues) immediately after use and 
then perform hand hygiene; improve airflow and ventilation in the living space by opening windows as much as possible.

\section{Health care settings}

Symptomatic people visiting a health care setting should wear a medical mask while waiting in triage or other areas and during transportation within the facility; they should not wear a medical mask when isolated in a single room, but cover their mouth and nose when coughing or sneezing with disposable paper tissues. Tissues must be disposed of appropriately, and hand hygiene should be performed immediately afterward (83). Health care workers should wear a medical mask when entering a room where patients with suspected or confirmed COVID-19 are admitted. They should use a particulate respirator, at least as protective as a US National Institute for Occupational Safety and Health certified N95, European Union standard FFP2, or equivalent when performing or working in settings where aerosol-generating procedures, such as tracheal intubation, non-invasive ventilation, tracheotomy, cardiopulmonary resuscitation, manual ventilation before intubation, and bronchoscopy are performed. Full infection prevention and control guidance for health care workers have been previously described (86).

\section{National Response}

The government's response to the outbreak has mainly followed standard lines. The Government has set up a Presidential Task Force for COVID19 , with the Nigerian Centre for Disease Control as the main technical organ for control of the pandemic in Nigeria. The Government has mobilized the country's polio response infrastructure (87) to support the ongoing effort against COVID-19. This infrastructure has over 700 disease notification and surveillance officers. The polio staff is to interphase with the communities to ensure that contact tracing and symptomatic people are quickly attended to. In addition to this, communication with the communities has been enhanced with the support of cell phone companies who carry out advertisements and advice on COVID-19 with virtually each telephone call. The government has advised people to wear masks, do self-isolation, maintain social distancing, and then report in health care facilities if they have a fever and a cough, and voluntarily turn up for diagnosis. There is a very heavy emphasis on handwashing, with water or sanitizers. All public places do this religiously and enthusiastically. The current number of NCDC accredited diagnostic centers are, without a doubt, too few for a country of over 170 million people. Unfortunately, people do not see COVID-19 as a true epidemic, or pandemic, therefore, they don't think they could be infected. The issue of social distancing is difficult for many Nigerians, as this is a new cultural norm that will be difficult to enforce.

On the other hand, some States in Nigeria must be commended as Lagos State is in a lockdown, which is being enforced and backed by law. Also, many of the top civil servants in Lagos who have had contact are maintaining self-isolation. The Federal Government has enforced lockdown in some states. Nevertheless, in contrast to these efforts some people in the society feel they are above the rules of the Government and are damaging societal efforts to combat this pandemic. The government needs to up its efforts on aggressive far-reaching awareness and health education on the COVID-19 pandemic. The National Orientation Agency, NOA, and other well-meaning non-governmental organizations should all act to complement the government's efforts.

The response of the scientific world has to be commended as scientists are busy trying to develop new ways of fighting the pandemic. Putative drugs to combat COVID-19 are currently being tested. Some of them are old drugs that do not need new registration but will be registered for a new indication. Two of these are chloroquine/hydroxychloroquine and ivermectin. The race towards a deployable vaccine is going on rapidly. As promising as these drugs may look, the WHO and other leading Health regulators, and gladiators including the Nigeria CDC have called for randomized clinical trials in countries' local settings and uniqueness to determine the safety and efficacy of such products.

\section{Conclusion}

With the spread of COVID-19 being slow and incidence low up till the present time, several questions arise. First, although we have a paucity of data, we are convinced there is very gross under-reporting of the disease. This is because Nigeria is not poised to tackle this level or spread of epidemics. Secondly, there is a shortage of manpower in the critical areas needed to fight the epidemic. These are in the areas of data collection and investigation, and hospital and health care management capabilities. For example, the rapidity with which facilities were expanded and converted into use for infectious diseases in Italy, doesn't exist in Nigeria (47). 
The big question on everybody's mind is, do we have a simmering epidemic that is being transmitted in the suburbs of our township? If not, do we already have herd immunity from a COVID19-like virus from some of our domesticated animals? If in the coming weeks, we do not see an explosion in the number of cases, then there is rationale investigating the last option.

\section{List of abbreviation:}

\begin{tabular}{|c|c|}
\hline BAL: & broncho-alveola lavage \\
\hline COVID-19: & Coronavirus Disease 2019 \\
\hline FFP: & Filtering face pieces \\
\hline MERS-CoV: & $\begin{array}{l}\text { Middle East respiratory } \\
\text { syndrome coronavirus }\end{array}$ \\
\hline Ncov & novel coronavirus \\
\hline CR: & $\begin{array}{l}\text { Reverse transcription } \\
\text { polymerase chain reactions }\end{array}$ \\
\hline SARS-CoV: & $\begin{array}{l}\text { severe acute respiratory } \\
\text { syndrome coronavirus }\end{array}$ \\
\hline 3-CoV-2: & $\begin{array}{l}\text { severe acute respiratory } \\
\text { syndrome coronavirus } 2\end{array}$ \\
\hline & $\begin{array}{l}\text { peripheral capillary oxygen } \\
\text { saturation }\end{array}$ \\
\hline
\end{tabular}

\section{Declarations}

Ethics approval and consent to participate Not applicable.

\section{Consent for Publication}

The authors hereby transfer all copyright ownership exclusively to the journal, if this work is published by the journal.

\section{Conflicts of Interest}

The authors have declared no conflict of interest.

\section{Funding}

The authors received no research funding.

\section{Authors Contributions}

CJE was responsible for data review and statistics, and writing of the manuscript. OW was responsible for data review and writing of the manuscript.

\section{Reference}

1. World Health Organization (WHO). Novel Coronavirus (2019-nCoV ) Situation Report 2211 February 2020 [Internet]. WHO Bulletin. 2020 [cited 2020 Apr 7]. p. 1-7. Available from: https://who.int/emergencies/diseases/novelcoronavirus-2019.

2. World Health Organization (WHO). Naming the coronavirus disease (COVID-19) and the virus that causes it [Internet]. 2020 [cited 2020 Apr 11]. Available from: https://who.int/emergencies/diseases/novelcoronavirus-2019/technicalguidance/naming-the-coronavirus-disease(covid-2019)-and-the-virus-that-causes-it.

3. Gorbalenya AE, Baker SC, Baric RS, de Groot RJ, Drosten C, Gulyaeva AA, et al. Severe acute respiratory syndrome-related coronavirus: The species and its viruses-a statement of the Coronavirus Study Group. biorxiv.org [Internet]. 2020 [cited 2020 Apr 11];1-15. https://doi.org/10.1101/2020.02.07.937862.

4. World Health Organization (WHO). WHO COVID-19 Dashboard [Internet]. [cited 2020 Apr 11]. Available from: https://who.sprinklr.com.

5. JHU COVID-19 Resource Center. Coronavirus COVID-19 (2019-nCoV) [Internet]. 2020 [cited 2020 Apr 11]. Available from:

https://gisanddata.maps.arcgis.com/apps/op sdashboard/index.html\#/bda7594740fd4029 9423467b48e9ecf6.

6. Worldometer. Coronavirus Update (Live): 1,872,027 Cases and 116,017 Deaths from COVID-19 Virus Pandemic - Worldometer [Internet]. [cited 2020 Apr 13]. Available from: https://www.worldometers.info/coronavirus.

7. Nickol ME, Kindrachuk J. A year of terror and a century of reflection: Perspectives on the great influenza pandemic of 1918-1919. BMC Infectious Diseases. 2019. https://doi.org/10.1186/s12879-019-3750-8.

8. Li J, You Z, Wang Q, Zhou Z, Qiu Y, Luo R, et al. The COVID-19 resource centre is hosted on Elsevier Connect, the company 's public news and information. 2020;(January). https://doi.org/10.14293/s2199-1006.1.sormed.clkmnzy.v1.

9. Lake MA. What we know so far: COVID-19 current clinical knowledge and research. Clin Med. 2020;20(2):124-7. https://doi.org/10.7861/clinmed.2019-coron.

10. World Health Organization (WHO). Novel Coronavirus ( 2019-nCoV ) Situation Report 121 January 2020 [Internet]. WHO Bulletin. 2020 [cited 2020 Apr 6]. p. 1-7. Available from:

https://who.int/emergencies/diseases/novelcoronavirus-2019.

11. Drosten C, Günther S, Preiser W, Van der Werf S, Brodt HR, Becker $S$, et al. 
Identification of a novel coronavirus in patients with severe acute respiratory syndrome. N Engl J Med. 2003;348(20):1967-76.

12. Cui J, Li F, Shi ZL. Origin and evolution of pathogenic coronaviruses. Nat Rev Microbiol [Internet]. 2019;17(3):181-92. Available from: http://dx.doi.org/10.1038/s41579-0180118-9.

13. Ye Z-W, Yuan S, Yuen K-S, Fung S-Y, Chan $C-P$, Jin D-Y. Zoonotic origins of human coronaviruses. Int J Biol Sci. 2020;16(10):1686-97. https://doi.org/10.7150/ijbs.45472.

14. Zhou P, Yang X Lou, Wang XG, Hu B, Zhang $L$, Zhang $W$, et al. A pneumonia outbreak associated with a new coronavirus of probable bat origin. Nature [Internet]. 2020;579(7798):270-3. http://dx.doi.org/10.1038/s41586-020-20127.

15. Mackenzie JS, Smith DW. COVID-19: a novel zoonotic disease caused by a coronavirus from China: what we know and what'we don't. Microbiology Australia 2020;41(1)

45-50

https://doi.org/10.1071/ma20013.

16. Douglas D. Richman, Richard J. Whitley FGH, editor. CLINICAL VIROLOGY FOURTH EDITION [Internet]. 4th editio. International Encyclopedia of Public Health. ASM Press Washington, DC; 2016. 1-1489 p. Available from: http://www.asmscience.org.

17. Tyrrell DAJ, Bynoe ML. Cultivation of viruses from a high proportion of patients with colds. Lancet [Internet]. 1966 Jan 8;287(7428):76$7 . \quad$ https://doi.org/10.1016/S01406736(66)92364-6.

18. blab/sars-like-cov Nextrain. Phylogeny of SARS-like betacoronaviruses including novel coronavirus SARS-CoV-2 [Internet]. 2020 [cited 2020 Apr 7]. Available from: https://nextstrain.org/groups/blab/sars-likecov.

19. Velavan TP, Meyer CG. The COVID-19 epidemic. Trop Med Int Heal. 2020;25(3):278-80. https://doi.org/10.1111/tmi.13383.

20. Singhal T. A Review of Coronavirus Disease2019 (COVID-19). Indian J Pediatr. 2020;87(4):281-6.

https://doi.org/10.1007/s12098-020-03263-6

21. Chan-Yeung $M, \quad X u$ RH. SARS: Epidemiology. Respirology. 2003 8:S9-S14. https://doi.org/10.1046/i.14401843.2003.00518.x.s

22. World Health Organization (WHO). Mers Situation Update November 2019 [Internet]. WHO Bulletin. 2019 [cited 2020 Apr 8]. p. 22765492. Available from: https://who.int/emergencies/mers-cov/en/.

23. Lu R, Zhao X, Li J, Niu P, Yang B, Wu H, et al. Genomic characterisation and epidemiology of 2019 novel coronavirus: implications for virus origins and receptor binding. Lancet. $2020 \quad$ Feb 22;395(10224):565-74.

https://doi.org/10.1016/S01406736(20)30251-8.

24. Chan JFW, Yuan S, Kok KH, To KKW, Chu $\mathrm{H}$, Yang $\mathrm{J}$, et al. A familial cluster of pneumonia associated with the 2019 novel coronavirus indicating person-to-person transmission: a study of a family cluster. Lancet [Internet]. 2020;395(10223):514-23. Available from: http://dx.doi.org/10.1016/S01406736(20)30154-9.

25. Ceraolo C, Giorgi FM. Genomic variance of the 2019-nCoV coronavirus. J Med Virol. 2020 May 1;92(5):522-8. https://doi.org/10.1002/jmv.25700

26. Rothan HA, Byrareddy SN. The epidemiology and pathogenesis of coronavirus disease (COVID-19) outbreak. J Autoimmun. 2020;109:18-21.

https://doi.org/10.1016/j.jaut.2020.102433.

27. World Health Organization (WHO). Report of the WHO-China Joint Mission on Coronavirus Disease 2019 (COVID-19) [Internet]. 2020 [cited 2020 Apr 11]. https://doi.org/10.3410/f.737509210.793572 110.

28. Hu B, Zeng LP, Yang X Lou, Ge XY, Zhang $W$, Li B, et al. Discovery of a rich gene pool of bat SARS-related coronaviruses provides new insights into the origin of SARS coronavirus. PLoS Pathog. 2017 Nov 1;13(11). https://doi.org/10.1371/journal.ppat.1006698

29. L̇au SKP, Feng Y, Chen H, Luk HKH, Yang W-H, Li KSM, et al. Severe Acute Respiratory Syndrome (SARS) Coronavirus ORF8 Protein Is Acquired from SARS-Related Coronavirus from Greater Horseshoe Bats through Recombination. J Virol. 2015 Oct 15;89(20):10532-47. https://doi.org/10.1128/jvi.01048-15.

30. Luk HKH, Li X, Fung J, Lau SKP, Woo PCY. 
Molecular epidemiology, evolution and phylogeny of SARS coronavirus. Infect Genet Evol [Internet]. 2019 Jul 1 [cited 2020 Apr 12];71:21-30.

https://doi.org/10.1016/j.meegid.2019.03.00 1.

31. Lau SKP, Li KSM, Huang Y, Shek C-T, Tse $H$, Wang $M$, et al. Ecoepidemiology and Complete Genome Comparison of Different Strains of Severe Acute Respiratory Syndrome-Related Rhinolophus Bat Coronavirus in China Reveal Bats as a Reservoir for Acute, Self-Limiting Infection That Allows Recombination Events. J Virol. 2010 Mar 15;84(6):2808-19. https://doi.org/10.1128/jvi.02219-09.

32. Ge XY, Li JL, Yang X Lou, Chmura AA, Zhu $\mathrm{G}$, Epstein $\mathrm{JH}$, et al. Isolation and characterization of a bat SARS-like coronavirus that uses the ACE2 receptor. Nature. 2013;503(7477):535-8. https://doi.org/10.1038/nature12711

33. Yu P, Hu B, Shi Z-L, Cui J. Geographical structure of bat SARS-related coronaviruses. Infect Genet Evol [Internet]. 2019 Apr 1 [cited 2020 Apr 12];69:224-9. https://doi.org/10.1016/j.meegid.2019.02.00 1.

34. National Bureau of Statistics. NATIONAL BUREAU OF STATISTICS [Internet]. 2020 [cited 2020 Apr 8]. Available from: http://nigerianstat.gov.ng/

35. Welcome M. The Nigerian health care system: Need for integrating adequate medical intelligence and surveillance systems. J Pharm Bioallied Sci [Internet]. 2011 Oct [cited 2020 Apr 12];3(4):470. https://doi.org/10.4103/0975-7406.90100. http://www.jpbsonline.org/text.asp?2011/3/4/ $470 / 90100$

36. World Health Organization (WHO). The Nigeria health system [Internet]. [cited 2020 Apr 12]. Available from: https://who.int/pmnch/countries/nigeria-planchapter-3.pdf.

37. World Health Organization (WHO). WHO | Nigeria. Workforce alliance [Internet]. [cited 2020 Apr 12]. Available from: https://www.who.int/workforcealliance/countr ies/nga/en/.

38. Adeloye D, David RA, Olaogun AA, Auta A, Adesokan A, Gadanya M, et al. Health workforce and governance: The crisis in Nigeria. Hum Resour Health [Internet]. 2017 May 12 [cited 2020 Apr 12];15(1):32. https://doi.org/10.1186/s12960-017-0205-4
39. Nigeria Centre for Disease Control (NCDC). An Update of COVID-19 Outbreak in Nigeria for week 12, 18th March 2020. 2020;(009):13. 109x(20)30101-7.

https://doi.org/10.1016/s2214-

40. Nigeria Centre for Disease Control (NCDC). NCDC Coronavirus (COVID-19) Information Minisite [Internet]. 2020 [cited 2020 Apr 11]. Available from: https://covid19.ncdc.gov.ng/.

41. Guo Y-R, Cao Q-D, Hong Z-S, Tan Y-Y, Chen S-D, Jin $\mathrm{H}-\mathrm{J}$, et al. The origin, transmission and clinical therapies on coronavirus disease 2019 (COVID-19) outbreak - an update on the status. Mil Med Res. 2020;7(1):1-10. https://doi.org/10.1186/s40779-020-00240-0.

42. Zu ZY, Jiang M Di, Xu PP, Chen W, Ni QQ, Lu GM, et al. Coronavirus Disease 2019 (COVID-19): A Perspective from China. Radiology. 2020;2019:200490. https://doi.org/10.1148/radiol.2020200490.

43. Goh KJ, Choong MC, Cheong EH, Kalimuddin S, Duu Wen S, Phua GC, et al. Rapid Progression to Acute Respiratory Distress Syndrome: Review of Current Understanding of Critical IIIness from COVID19 Infection. Ann Acad Med Singapore. 2020;

44. Statista. - Coronavirus cases worldwide 2020 | Statista [Internet]. 2020 [cited 2020 Apr 13]. Available from: https://www.statista.com/statistics/1043366/ novel-coronavirus-2019ncov-casesworldwide-by-countryl.

45. Nigeria Centre for Disease Control (NCDC). COVID-19 SITUATION REPORT SITUATION REPORT 41 STATE OF THE NATION. 2020;17-9.

46. Worldometer. Coronavirus Age, Sex, Demographics (COVID-19) - Worldometer [Internet]. 2020 [cited 2020 Apr 13]. Available from:

https://www.worldometers.info/coronavirus/c oronavirus-age-sex-demographics/.

47. Asperges E, Novati S, Muzzi A, Biscarini S, Sciarra M, Lupi M, et al. Rapid response to COVID-19 outbreak in Northern Italy: how to convert a classic infectious disease ward into a COVID-19 response centre. J Hosp Infect. 2020; https://doi.org/10.1016/j.jhin.2020.03.020.

48. Tuite AR, Ng V, Rees E, Fisman D. Correspondence Estimation of COVID-19 outbreak size in Italy. Lancet Infect Dis. 2020;3099(20):30227.

https://doi.org/10.1016/s14733099(20)30227-9. 
49. Deng S-Q, Peng H-J. Characteristics of and Public Health Responses to the Coronavirus Disease 2019 Outbreak in China. J Clin Med. 2020;9(2).

https://doi.org/10.3390/jcm9020575.

50. Wang D, Hu B, Hu C, Zhu F, Liu X, Zhang J, et al. Clinical Characteristics of 138 Hospitalized Patients with 2019 Novel Coronavirus-Infected Pneumonia in Wuhan, China. JAMA - J Am Med Assoc [Internet]. 2020 Mar 17 [cited 2020 Apr 8];323(11):1061-9. https://doi.org/10.1001/jama.2020.1585.

51. Chen N, Zhou M, Dong X, Qu J, Gong F, Han $Y$, et al. Epidemiological and clinical characteristics of 99 cases of 2019 novel coronavirus pneumonia in Wuhan, China: a descriptive study. Lancet. 2020 Feb 15;395(10223):507-13. https://doi.org/10.1016/s01406736(20)30211-7.

52. Nigeria Centre for Disease Control (NCDC). NATIONAL INTERIM GUIDELINES FOR CLINICAL MANAGEMENT OF COVID-19 VERSION 1. Components [Internet]. 2020;139. Available from: https://ncdc.gov.ng/.

53. Spina S, Marrazzo F, Migliari M, Stucchi R, Sforza A, Fumagalli R. The response of Milan's Emergency Medical System to the COVID-19 outbreak in Italy. Lancet [Internet]. 2020 [cited 2020 Apr 11];395:e49-50. https://doi.org/10.1016/s0140-

6736(20)30493-1.

54. Remuzzi A, Remuzzi G. Since January 2020 Elsevier has created a COVID-19 resource centre with free information in English and Mandarin on the novel coronavirus COVIDresearch that is available on the COVID-19 resource centre - including this for unrestricted research re-use a. 2020; (January). https://doi.org/10.1016/s01406736(20)30627-9.

55. Rudan I. A cascade of causes that led to the COVID-19 tragedy in Italy and in other European Union countries. J Glob Health [Internet]. 2020 [cited 2020 Apr 13];10(1). https://doi.org/10.7189/jogh.10.010335.

56. Hu Y, Liang W, Liu L, Li L. Clinical Characteristics of Coronavirus Disease 2019 in China. N Engl J Med [Internet]. 2020 [cited 2020 Apr 13];

57. Li Q, Guan X, Wu P, Wang X, Zhou L, Tong $Y$, et al. Early Transmission Dynamics in Wuhan, China, of Novel CoronavirusInfected Pneumonia. N Engl J Med.
2020;382(13):1199-207.

58. Li Q, Guan X, Wu P, Wang X, Zhou L, Tong $Y$, et al. Early Transmission Dynamics in Wuhan, China, of Novel CoronavirusInfected Pneumonia. N Engl J Med. 2020;1920.

59. Onder G, Rezza G, Brusaferro S. CaseFatality Rate and Characteristics of Patients Dying in Relation to COVID-19 in Italy. JAMA - Journal of the American Medical Association. 2020. https://doi.org/10.1001/jama.2020.4683

60. Bernard Stoecklin S, Rolland $P$, Silue $Y$, Mailles A, Campese C, Simondon A, et al. First cases of coronavirus disease 2019 (COVID-19) in France: surveillance, investigations and control measures, January 2020. Euro Surveill. 2020;25(6). https://doi.org/10.2807/15607917.es.2020.25.6.2000094.

61. Spiteri G, Fielding J, Diercke M, Campese C, Enouf V, Gaymard A, et al. First cases of coronavirus disease 2019 (COVID-19) in the WHO European Region, 24 January to 21 February 2020. Euro Surveill. 2020;25(9).

62. World Health Organization (WHO). National laboratories [Internet]. 2020 [cited $2020 \mathrm{Apr}$ 14]. Available from: https://www.who.int/emergencies/diseases/n ovel-coronavirus-2019/technicalguidance/laboratory-guidance.

63. Nigeria Centre for Disease Control (NCDC). CASE DEFINITIONS FOR COVID-19 (Version 4) [Internet]. 2020 [cited 2020 Apr 14]. Available from: https://ncdc.gov.ng/themes/common/docs/pr otocols/186 1584531606.pdf.

64. World Health Organization (WHO). Laboratory testing strategy recommendations for COVID-19: Interim guidance. 2020.

65. Wang W, Xu Y, Gao R, Lu R, Han K, Wu G, et al. Detection of SARS-CoV-2 in Different Types of Clinical Specimens [Internet]. JAMA - Journal of the American Medical Association. American Medical Association; 2020 [cited 2020 Apr 8]. https://doi.org/10.1001/jama.2020.3786.

66. World Health Organization (WHO). Protocol: Real-time RT-PCR assays for the detection of SARS-CoV-2.

67. Nigeria Centre for Disease Control (NCDC). Specimen Collection and transportation Guide: Coronavirus. 2020;1-8.

68. CNN. Phillipine. FDA approves 5 rapid test kits for COVID-19, but requires confirmatory 
test for samples [Internet]. [cited $2020 \mathrm{Apr}$ 14]. Available from: https://www.cnnphilippines.com/news/2020/ 3/30/FDA-rapid-test-kits.html.

69. Jovanovich S, Horn J. Microfluidics Applications in Biodefense. Available from: https://link.springer.com/content/pdf/10.1007 \%2F978-0-387-09480-9 10.pdf

70. Cepheid. Cepheid | Xpert $囚$ Xpress SARSCoV-2 has received FDA Emergency Use Authorization [Internet]. [cited 2020 Apr 14]. Available https://www.cepheid.com/coronavirus.

71. NHS. Guidance and Standard Operating Procedure COVID-19 Virus Testing in NHS Laboratorie [Internet]. [cited $2020 \mathrm{Apr} 14]$. https://doi.org/10.1136/bmi.m1339.

72. Huang $P$, Liu T, Huang L, Liu H, Lei M, Xu W, et al. Use of Chest CT in Combination with Negative RT-PCR Assay for the 2019 Novel Coronavirus but High Clinical Suspicion. Radiology [Internet]. 2020 Apr 12 [cited 2020 Apr 14];295(1):22-3. https://doi.org/10.1148/radiol.2020200330.

73. Lythgoe MP, Middleton P. Ongoing Clinical Trials for the Management of the COVID-19 Pandemic. Trends Pharmacol Sci [Internet]. 2020 Apr [cited 2020 Apr 16];0(0). Available from:

https://linkinghub.elsevier.com/retrieve/pii/S0 165614720300705.

74. Dailymail.co.uk. You CAN take ibruprofen to treat coronavirus, Government panel of experts concludes | Daily Mail Online [Internet]. [cited 2020 Apr 14]. Available from: https://www.dailymail.co.uk/health/article8218663/You-ibruprofen-treat-coronavirusGovernment-panel-experts-concludes.html.

75. Centers for Disease Control and Prevention CDC. Quarantine and Isolation | Quarantine | CDC [Internet]. [cited 2020 Apr 14]. Available from:

https://www.cdc.gov/quarantine/index.html.

76. JHU Quarantine self. How families and roommates can effectively self-quarantine, self-isolate | Hub [Internet]. [cited 2020 Apr 14]. Available from: https://hub.jhu.edu/2020/03/23/how-to-selfquarantine-self-isolate/.

77. Parmet WE, Sinha MS. Covid-19 - The Law and Limits of Quarantine. N Engl J Med. 2020 Mar 18; Availabel at: https://nejm.org/doi/full/10.1056/NEJMp2004 211.

78. Gostin LO, Hodge JG. US Emergency Legal Responses to Novel Coronavirus: Balancing
Public Health and Civil Liberties. JAMA 2020 Mar $24 \quad 323(12): 1131-1132$. https://doi.org/10.1001/jama.2020.2025

79. Nigeria. Nigeria QUARANTINE ACT 1926 [Internet]. [cited 2020 Apr 15]. Available from: http://lawsofnigeria.placng.org/laws/Q2.pdf.

80. World Health Organization (WHO). Situation Report-73 HIGHLIGHTS [Internet]. 2020 [cited $2020 \mathrm{Apr}$ 15]. Available from: https://www.who.int/docs/defaultsource/coronaviruse/situationreports/20200402-sitrep-73-covid19.pdf?sfvrsn=5ae25bc7 6 .

81. Yu P. A Familial Cluster of Infection Associated With the 2019 Novel Coronavirus Indicating Potential Person-To-Person Transmission During the Incubation Period PubMed [Internet]. [cited 2020 Apr 15]. https://doi.org/10.1093/infdis/jiaa077.

82. Huang R, Xia J, Chen Y, Shan C, Wu C. A family cluster of SARS-CoV-2 infection involving 11 patients in Nanjing, China. The Lancet Infectious Diseases. Lancet Publishing Group; 2020. https://doi.org/10.1016/s14733099(20)30147-x.

83. World Health Organization. Advice on the use of masks in the context of COVID-19: interim guidance, 6 April 2020. World Health Organization; 2020. Available at: https://apps.who.int/iris/bitstream/handle/106 65/331693/WHO-2019-nCov-IPC_Masks2020.3-eng.pdf? sequence=1\&isAllowed=y.

84. Suess T, Remschmidt C, Schink SB, Schweiger B, Nitsche A, Schroeder K, et al. The role of facemasks and hand hygiene in the prevention of influenza transmission in households: Results from a cluster randomised trial; Berlin, Germany, 20092011. BMC Infect Dis. 2012 Jan 26;12. https://doi.org/10.1186/1471-2334-12-26.

85. Aiello AE, Murray GF, Perez V, Coulborn RM, Davis BM, Uddin M, et al. Mask Use, Hand Hygiene, and Seasonal Influenza-Like Illness among Young Adults: A Randomized Intervention Trial. J Infect Dis. 2010 Feb 15;201(4):491-8. https://doi.org/10.1086/650396.

86. World Health Organization (WHO). Infection prevention and control of epidemic-and pandemic-prone acute respiratory infections in health care WHO Guidelines [Internet]. 2014 [cited 2020 Apr 15]. Available from: https://who.int/csr/bioriskreduction/infection control/publication/en/

87. World Health Organization (WHO). Nigeria's 
Elikwu et. al. BUMJ 2020 3(1):11-26

polio infrastructure bolster COVID-19 response | WHO | Regional Office for Africa [Internet]. World Health Organization. 2020

[cited 2020 Apr 9]. Available from: https://afro.who.int/news/nigerias-polioinfrastructure-bolster-covid-19-response. 